\title{
From Call to Mall: The Effectiveness of Podcast on EFL Higher Education Students' Listening Comprehension
}

\author{
Nada Al Qasim ${ }^{1} \&$ Hind Al Fadda ${ }^{1}$ \\ ${ }^{1}$ King Saud University, Saudi Arabia \\ Correspondence: Dr. Hind Al Fadda, King Saud University, Saudi Arabia. E-mail: hind.alfadda@gmail.com; \\ Nada Al Qasim, E-mail: n.alqasim@yahoo.com
}

Received: May 15, 2013 Accepted: June 24, 2013 Online Published: August 15, 2013

doi:10.5539/elt.v6n9p30 URL: http://dx.doi.org/10.5539/elt.v6n9p30

\begin{abstract}
Despite recognition that language can best be learned in an authentic context, and a growing emphasis on the importance of using technology to improve listening skills, only limited research in this area exists in a Saudi context. To add to this research, this quantitative study examines the influence of podcasting on the listening comprehension of 46 female Saudi EFL students in higher education. The randomly selected participants were divided into two groups: a control and an experimental group, and given a six week treatment. A T-test and questionnaire were employed, and the results indicate significant differences between the two groups, favoring the experimental group.
\end{abstract}

Keywords: EFL, listening comprehension, podcast, MALL, M-Learning

\section{Introduction}

\subsection{Background}

English is an international language, used by academic communities around the world, including those in Saudi Arabia. Accordingly, how best to meet the demands for EFL teaching and learning are increasingly being researched in Saudi Arabian universities. Despite the large number of English learners, EFL learning continues to follow an in-class-only learning model, with only rare opportunities afforded to EFL learners to use the language beyond the boundaries of the classroom. This indicates a need for practical incorporation of a student-centered approach to provide contextualized language learning (Al-Shehri, 2011).

To help address the limited opportunities for authentic conversation to promote listening skills, and in view of the advances in technology, the modern classroom is increasingly utilizing digital resources. In the higher education setting, the newest digital technologies are playing a significant role in shaping the teaching and learning landscape; e.g., MALL (Mobile Assisted Language Learning). According to Al-Fahad (2009), by 2004, cell phones had become an ever-present fixture in the lives of modern college students in Saudi Arabia. Now, greatly improved Wifi accessibility and $3 \mathrm{G}$ for mobiles has promoted the widespread adoption of smartphones.

In the learning arena, the ubiquitous presence of smart phones and similar devices has resulted in the design of multiple Mobile Learning (M-Learning) applications, which are currently emerging onto the market (Chang, Chen \& Yen, 2012). According to Howell and Lee (2007), the teaching resources available for mobiles include: SMS and Java quizzes, applications specifically designed as learning modules using M-learning software to assist in media collection via camera-phones, and audio-based learning (MP3 players and podcasting).

In the area of language teaching, applications for listening have become increasingly popular, and 'podcasting' in particular appeals to language learners; podcasts can provide additional up to date and authentic listening practice both inside and outside the classroom. Podcasting as an online communication technology is inspirational in this context; it gives learners control over their exploration processes and allows them to search for and discover motivational educational material independently (Kavaliauskiene , 2008). However, the applicability of mobile podcasting to English teaching requires further research; as to date, only a handful of studies have investigated the pedagogical use of M-Learning for listening comprehension (SZE, 2006; Kukulska-Hulme \& Lesley, 2007; Lu, 2007; Kavaliauskiene, 2008). 


\subsection{Statement of the Problem}

The results of a limited number of studies indicate continuing uncertainty regarding the effectiveness of podcasts as a language learning tool for improving undergraduate students' listening comprehension. Moreover, although many studies have described the use of podcasts in language learning, these have been undertaken internationally; thus, the number of studies in the Saudi context remains unsatisfactory. Research by Clark et al. (2009) claims that in order to increase the potential benefits of podcasting in higher education, there is a need to focus on the pedagogical design of podcasts, rather than on merely repeating lecture content, as it is important to give an active role to students. Thus, podcasts are seen to be most beneficial when introduced as part of a blended approach in which students are encouraged to generate their own recordings (Edirisingha, Fothergill \& Salmon, 2007; Burston, Song \& Zhang, 2011).

\subsection{Relevant Related Research}

The body of research that describes the benefits of podcasting also raises concerns in reference to its use in a pedagogical context. By detailing the findings, recommendations and limitations of other studies this section will highlight specific areas for further investigation, that will be considered in the remainder of this paper.

\subsubsection{Overview of Podcasts}

The New Oxford American Dictionary (Oxford University Press, 2005) defines podcast as: 'a multimedia digital file made available on the internet for downloading to a portable media player, computer, etc.'; and designated it the Word of the Year in 2005, owing to the rapid growth in the popularity of this broadcast medium over the course of that year (BBC, 2005). According to Chan, Lee and McLoughlin (2007), the term podcast was derived by blending the words iPod and broadcast. Podcasts can either be pure audio podcasts, video podcasts or enhanced podcasts; i.e. pictures, slideshows, PowerPoint, etc. According to Dennett et al. (2008) audio podcasts are the most popular source because they are free and easier to produce than video podcasts.

Podcasts differ from radio broadcasts in that the former are connected to a listening device by RSS (Really Simple Syndication) feeds, developed by Dave Winer in 1997. This means that once subscribed to a podcast via an RSS reader application, such as iTunes or Google Reader, the latest podcast episodes can be 'automatically downloaded to any MP3 player or mobile without having to go to the site' (Mahjouri \& Purnell, 2007). Thus, the emergence of podcasting was closely connected to the origination of RSS feeds (Pals, Randell \& Shawback, 2005).

In 1999, Winer cooperated with Adam Curry, the former MTV VJ, to extend the available technology to connect media content files to powerful tools such as XML and RSS feeds. In 2004, Curry developed a software programme to transfer audio recordings automatically directly onto an iPod to be stored alongside music. The integration of podcasts into Apple iTunes prompted thousands to emerge rapidly and EFL podcasting sites that had formerly received little attention became noticed as a result of their availability on iTunes.

\subsubsection{Podcasts as Language Learning Materials}

Rosell-Aguilar (2007) suggested that the podcast resources so far made available for language learning can be categorized into two main groups: the first consisting of authentic content provided by native speakers or advanced learners, not intended to teach language and referring to subjects such as news, football, or radio programming. The second group is comprised of language courses or teaching content specifically designed for language learning. The latter are classified into two subgroups: materials designed for a known audience, such as the materials provided by teachers, institutions or students themselves for use with their classes (which may include audio recordings of texts, oral quizzes, oral feedback, and vocabulary items) and supporting materials designed for independent learners not enrolled on a particular course that are delivered as public podcasts.

\subsubsection{Podcasts and EFL Learning Environments}

Four types of podcast can be identified as suitable for implementation in the EFL classroom, namely those relating to ESL, native English, test preparation (IELTS and TOEFL) and student production. ESL podcasts are those modified to teach English as a second language by providing audio lessons or topics, such as 'giving directions' or English idioms. Native English podcasts are not designed for pedagogical purpose, but do provide an authentic language learning context to fluent speakers. Using podcasts for test preparation is an option intended for universities that require their non-native speakers to pass an English test such as IELTS or TOEFL. Student-produced podcasts are different in that they rely on students to develop them as part of a task (McMinn, 2008). 


\subsubsection{EFL Podcasts and Motivation}

Hegelheimer and O-Bryan (2007) assert that podcasts can increase intrinsic and extrinsic motivation in students. Students experience intrinsic motivation when tasks appeal, because they are interesting and challenging and reward is found through enjoyment. In contrast, extrinsic motivation is achieved through the receipt of high grades or praise as a reward for learning. According to Sze (2007), once podcasts have been produced by students and uploaded online, they can then be downloaded by anyone around the world, thereby offering a wide audience and high intrinsic motivation. Moreover, producing podcasts is an authentic activity, allowing learners to communicate regarding topics discussed in their EFL classes, such as food, culture, body language, geography, animals, sports, habits and religion.

Chan, Lee and McLoughlin (2007) conducted a study, as part of a larger project at Charles Sturt University in Australia, which aimed to utilize podcasting as a pre-class listening material, to address the preconceptions and anxieties of university students with regards to lecture halls. A group of student volunteers undertook the challenge of the scriptwriting, editing and recording of the three to five minute audio clips. The podcasts were presented in a radio show style and were hosted in a relaxed and informal manner. The findings from the research demonstrated a better than anticipated uptake, with $82 \%$ of respondents reporting having played seven or more of the nine available podcasts from start to finish. Overall, the participants expressed a high level of agreement that the podcasts had educational value and that they had found them helpful for interpreting subject content. The respondents also asserted that the podcasts had high entertainment value and were desirable for use in a social context. The likelihood that the students would recommend the podcasts to others studying in the same field was also high and many of the respondents expressed an interest in becoming involved in producing podcasts themselves.

Later research by Chan, Chi, Chin and Lin (2011) involved two podcast projects conducted at a university in Singapore; these involved creating supplementary materials for use in class to teach Chinese and Korean as a foreign language. Data was collected from questionnaires administered to 120 Chinese and 61 Korean language students and from semi-structured interviews that focused on learners' perceptions of podcasts' quality and usefulness, and their attitudes towards podcast-based learning. Statistically significant differences were found in the perceptions and attitudes of the two groups of students. A comparison of the quantitative data from both projects demonstrated that the Korean students had more positive perceptions of the quality and usefulness of their course podcasts and a more positive attitude towards podcast-based learning than their Chinese counterparts. Data analysis uncovered four possible reasons for these differences: 1) the podcasts' objectives and the students' learning motivation; 2) a mismatch between podcast design and students' expectations, needs and preferences; 3 ) teacher encouragement and student preparation; and 4) prior experience of mobile learning.

\subsubsection{Podcasts and Attitude}

Li's investigation (2010) into the perceptions of 6 Hong Kong ESL secondary school students towards podcasts in the listening skills classroom, suggested a favorable response to the use of podcasts. One of the participants acknowledged that his listening skills and speaking skills had been enhanced, agreeing that podcasting was a useful tool to assist language learning. Li (2010) further stated that all the participants confirmed that they enjoyed listening to podcasts, with one student strongly agreeing that podcasts were easy to access. The emphasis of the learners in this study was largely positive, although there with concerns expressed over the length or style of the podcasts in some cases; thus, teachers must ensure that their choice of podcasts allows their students the best opportunity to take advantage of the medium's overwhelming benefits.

Menezes and Morera (2009) investigated $977^{\text {th }}$ grade students' attitudes towards podcasts in São Martinho in Porto, Portugal. Their participants enjoyed the episodes, replaying them frequently and commenting on each episode by giving their opinion in class. Perceptions of podcasts as an original feature of their studies were seen to increase students' motivation. However, this positive response contrasts with work by Clark et al. (2009) into the value of short-format podcasts to support the assessment of 30 postgraduate and 1548 undergraduate students, which overwhelmingly rejected podcasting in favor of traditional study practices. Reasons given in this study highlighted time pressures, students' English language skills and their understanding of the medium.

\subsubsection{Collaborative and Group Work}

Collaborative skills have come to be seen as a key generic asset in communicative based language teaching curriculums in many countries (Sze, 2006); this has led to emphasis on entering into a 'collaborative dialogue', a knowledge-building dialogue that delivers language learning opportunities (Rivera, 2010).

Stoltenkamp et al. (2011) proposed that more than one third of participants who engaged in collaborative work 
responded to the enjoyable and interactive nature of podcasts. Listening to their peers' 'recordings' enhanced both team work and the sense of collaboration; promoting engagement with the subject matter and the sharing of views. Fewer than ten percent of participants indicated that podcasts did not assist or improve interaction; these individuals commented that podcasting detracted from their academic work.

Research by Chan, Lee and McLoughlin (2007) demonstrated that students increased their efforts when they knew that their podcasts would be accessed by their peers. The process of writing and rewriting audio scripts involves making decisions, sharing ideas and mutual learning. Language errors and students' awareness of errors necessitates repeated recordings and is key to learners' progression.

\subsubsection{Using Podcasts for Enhancing Listening Comprehension}

Listening comprehension plays a critical role in language learning. It is not a passive activity, but rather a complex, active process in which the listener must discriminate between sounds and understand vocabulary and grammatical structures (Vandergrift, 1997). In addition, acquiring listening skills can be frustrating for students because the process is devoid of those rules inherent in grammar teaching. One of the largest inhibitors for students is the experience of a mental block, when required to make a sudden decision based on information they have heard and not understood. This causes many students to 'tune out' or convince themselves that they are unable to understand spoken English well, negatively affecting their motivation.

Over recent decades educators have employed both bottom-up and top-down interactive models to teach listening. However, researchers have expressed the belief that neither model is capable of addressing the intricacies of the listening process. Therefore attempts have been made to define a pedagogical model comprising contextualised, individual, social, cultural, affective, strategic and critical dimensions to support second language listening. In view of this, it is possible to understand why audio from the Internet has become an increasingly popular resource (Anusiené \& Kavaliauskiené, 2009).

Using podcasts as a medium for learning opens up new opportunities in the language learning context: research shows that audio content facilitates memory retention three times as effectively as a text. The auditory dimension of podcasting, e.g., intonation or vocal expression, conveys a message directly to the listener's heart and brain. The personal touch, including expression of emotions, feelings and tonal variations may contribute to a podcast message, in a way that cannot be achieved with a textual message (Panday, 2009). Podcasts benefit learners both with their spontaneity (Zarina, 2009) and their applicability to intensive and extensive listening tasks (Sze, 2006) Furthermore, the authenticity and type of materials available in this format effectively bridges the gap between formal English and informal language, making them suited to extensive listening, motivating students' interest in listening to English inside and outside the classroom.

A four week study by Lu (2007) to investigate how podcasts in both UK and US English could boost the listening and speaking proficiency of language learners in an EFL context involved a Taiwanese learner who had not previously been exposed to authentic English. The participant was asked to transcribe the podcasts, to identify vocabulary and grammar in context, and a discussion of the topics was conducted in English at the end of each week. The study revealed that using podcasts in listening instruction in this way has a positive impact; the participant gained confidence in his ability to comprehend English overall.

A similar investigation by Anusiené and Kavaliauskiené, (2009) scrutinized the problems encountered by students listening to authentic English podcasts, to analyses learners' self-evaluation of various techniques for improving listening skills. The participants in this study had different areas of specialization within the domain of English for Specific Purposes. The findings proved that the students' self-evaluation was realistic, and their positive attitudes and techniques for improving listening skills included listening to podcasts.

\subsubsection{Summary of Literature Review}

On the evidence provided, we can conclude that using podcasts for teaching allows the possibility of numerous positive outcomes. Individuals listening online to podcasts can listen at their own pace outside the classroom in a way that is convenient to them, without external assistance or judgment from their teachers or peers, thus maximizing motivation. Furthermore, by working independently learners are likely to become more aware of their personal learning styles and thereby discover how best they can perfect their own listening skills and promote their own language learning. By engaging in online listening as a complement to classroom activities, all learners regardless of level can observe benefits. This is heightened by allowing learners to decide how extensively they pursue listening tasks and which tasks to undertake. As mentioned above, the use of podcasts should be guided by teacher selection and the setting of tasks appropriate to the group of learners.

By investigating the benefits of podcasting by employing a statistical analysis to a Saudi sample, this research 
will provide a quantitative study concerning a new population to the growing bank of studies on podcasting.

\subsection{Research Questions:}

The study has been designed to answer the following questions:

1) Is podcasting effective for enhancing the listening comprehension skills of EFL higher education students?

2) Does podcasting enhance motivation among EFL higher education students in EFL classrooms, regarding listening comprehension?

3) What are EFL higher education students' attitudes towards using podcasts in EFL classrooms, regarding listening comprehension?

\section{Methodology}

\subsection{Participants}

The participants selected for this research were 46 female specialized undergraduate English learners in the College of Languages and Translation at King Saud University. The students attended English major courses and most of were at level three studying for up to 20 hours per week. The participants' ages ranged from 19 to 23 and they had studied English for at least six years before enrolling on the course, two years prior to this study. None of the 46 participants had had experience listening or downloading podcasts before implementing this study. All the participants in the experimental group had the necessary mobile hardware (Blackberry $(40 \%)$, iPad (20\%), iPhone (16\%), Galaxy (4\%), iPod (4\%)), software and Internet access to allow them to download podcasts on the move. By identifying device types, it was possible to provide the appropriate RSS feed applications.

The control group was composed of 21 participants, who were given no special treatment; whereas the experimental group of 25 participants received podcasts on their mobiles. Both groups were studying listening comprehension with the same teacher, and a pre-test based on their course book was administered to them. In the pre-test test, both control and experimental groups performed similarly. The mean score obtained by the experimental group for both parts of the pre-test test (11.52) was lower than the mean for the control group (11.71), as Table 1 illustrates:

Table 1. Independent sample t-test results for the differences between the two groups in the pre test

\begin{tabular}{lllllll}
\hline Test type & Group & $\mathrm{N}$ & Mean & Std. Deviation & T Value & Sig. \\
\hline \multirow{2}{*}{ Pretest } & Control & 21 & 11.71 & 2.43 & -.309 & .752 \\
& Experimental & 25 & 11.52 & 1.82 & & \\
\hline
\end{tabular}

*Significant at 0.05 level

However, these differences were not statistically significant, as can be seen from the results of the T-test for the independent sample $(.752 \mathrm{p}<.05)$.

\subsection{Materials}

The experimental group were encouraged to work in groups to create their own academic podcast channel for their peers with the assistance of the researcher. The podcast topics were selected from the students' syllabus: 'Mosaic 1 Listening and Speaking', and related to listening strategies and functions. Topics including making predictions, offering clarification, asking for confirmation, generalizing and expressing opinions. The vocabulary items were chosen by the students, who explained the syllabus topics and related them to their own lives by giving examples and asking their listeners questions.

\subsection{Instruments}

\subsubsection{Pre and Post-Tests}

The pre-test consisted of a 15 -item proficiency test covering listening comprehension and vocabulary items, with the purpose of determining the students' level in the target language. The maximum score for this test was 15 (see Table 1. above for results). The post-test, that was held six weeks later, was the same and designed to measure the effectiveness of podcasts as a teaching strategy (see Table 2. below for results).

\subsubsection{Questionnaire}

A questionnaire was given to the experimental group as a post-project evaluation to measure motivation and students' attitudes towards using podcasts as a learning strategy for their listening class. The questionnaire 
comprised 30 items. Mean scores for a selection of 5-point Likert-type items were intended to reflect the students' motivation. The maximum and the minimum boards of each scale were:

1) Means from (1.00-1.80) mean strongly disagree.

2) Means from (1.80-2.60) mean disagree.

3) Means from (2.60-3.40) mean neutral.

4) Means from (3.40-4.20) mean agree.

5) Means from (4.20-5.00) mean strongly agree.

(Taken from Al-Omar, 2004, p.126-127)

The reliability test for the instrument produced a Cronbach Alpha of 0.902, which can be considered highly reliable.

\subsection{Design}

The participants entitled their podcast channel 'Room 409' (see figures below) in reference to their classroom number. The researcher met with the volunteer participants outside their classroom in their free time. The software used to record the episodes was 'GarageBand', MAC software.

Within one hour, each group was practicing their scripts together and repeatedly rehearsing before the final recording. The podcasts ranged in length from 2-5 minutes (see figure 1) and all the episodes were audio formatted. Once completed, the researcher uploaded the episode weekly to two locations: iTunes [https://itunes.apple.com/us/podcast/po dcast-room-409/id573679571] (see figure 2) using XML (click here to find the XML file for the podcast channel); and a blog, using the RSS feed [http://feed.podcastroom409.wordpress.com].(see figures $3 \& 4$ )



Figure 1. Podcast channel on podcasts app on iPhone

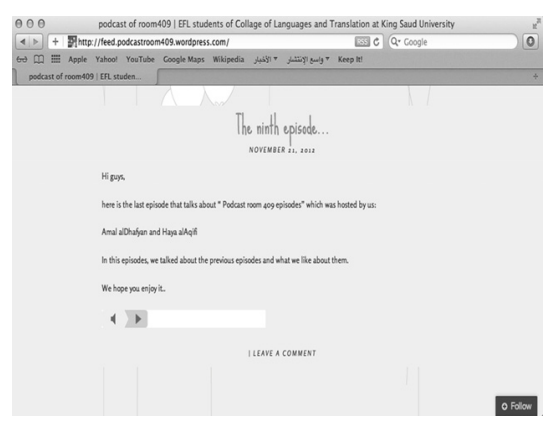

Figure 3. Podcast's blog on the internet

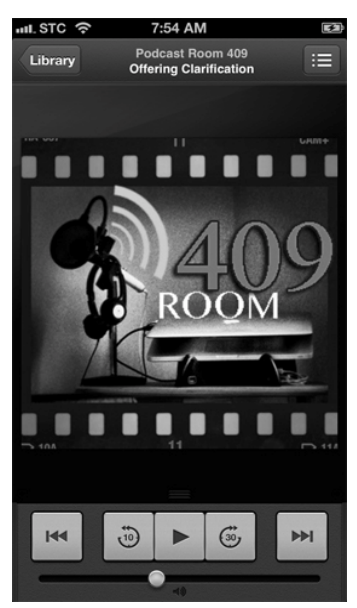

Figure 2. Podcast episodes were automatically downloaded on podcasts on iPhone after subscription

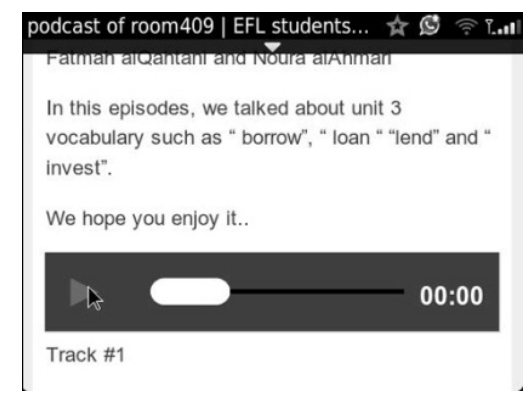

Figure 4. Podcast episodes were automatically downloaded on podcasts on Blackberry after subscription to the blog 
Subscription to RSS feeds on their mobile devices enabled the participants to access and listen to episodes created by them or their friends. The total number of podcasts was nine by the end of the six-week treatment. Students wrote their own podcast episode scripts and these were recorded under supervision by the researcher. The style of the podcast resembled a radio show.

\subsection{Procedure}

Initially, 10 participants volunteered to create the podcasts; however, by the end of the experiment most of the 25 participants in the experimental group had been able to create their own podcasts on demand successfully. All the participants were able to access and listen to the podcasts via RSS on their mobiles, once they had been uploaded to the internet. Six weeks later, the participants took a delayed post-test and completed a questionnaire without prior notice.

\section{Results and Discussion}

\subsection{Testing Question One}

The aim here is to evaluate responses to the enquiry into whether podcasting is effective for enhancing the listening comprehension skills of EFL students in higher education. Statistically significant differences were investigated by means of an independent sample test $\mathrm{T}$; this identified differences in the pre- and post-tests to conclude the research findings. At the start of the study, the pre-test suggested no relevant differences between the two groups; therefore, it is reasonable to suppose that any post-test differences would be a consequence of the treatment.

Table 2. Independent sample t-test results showing the differences between the two groups in the post-test

\begin{tabular}{lllllll}
\hline Test type & Test & $\mathrm{N}$ & Mean & Std. & T Value & Sig. \\
\hline \multirow{2}{*}{ Post-test. } & Control. & 21 & 11.62 & 2.941 & \multirow{2}{*}{3.427} & \multirow{2}{*}{.002} \\
\cline { 2 - 5 } & Experimental & 25 & 13.96 & 1.172 & & \\
\hline
\end{tabular}

*Significant at 0.05 level

Table 2 reveals that the experimental group performed better on the post-test $(M=13.96)$ than the control group $(\mathrm{M}=11.62)$. There was also a significant difference at $\mathrm{p}<0.05$ for the two groups' test scores. This indicates that the experimental group outperformed the control group in terms of listening comprehension. The standard deviation for the control group was (2.94), while it was (1.17) for the experimental group.

\subsection{Testing Question Two}

In order to answer the second question raised in the study a questionnaire was used to calculate the podcast uptake level and the learners' motivation. The question was: Does podcasting enhance motivation among students in EFL classrooms, regarding listening comprehension?

Table 3. Podcast questionnaire results: uptake levels $(\mathrm{N}=25)$

\begin{tabular}{lllll}
\hline To date, how many of the available podcasts have you... & Mean & \multicolumn{4}{l}{ Median } & Mode & Std Dev \\
\hline Q1: Downloaded (total)? & 7.16 & 9.00 & 9 & 2.688 \\
Q2: Downloaded and listened to from start to finish? & 6.24 & 6.00 & 6 & 2.505 \\
Q3: Downloaded and listened to part only? & .88 & .00 & 0 & 1.361 \\
Q4: Downloaded and listened to multiple times? & 1.88 & 1.00 & 2 & 2.386
\end{tabular}

$* \mathrm{~N}=25$ : 9 Podcasts released in total.

As Table 3 shows, the uptake level for the podcasts was good. $80 \%$ of participants reported that they had listened to seven or more of the nine episodes. $70 \%$ of participants reported that they had listened to six or more of the nine available podcasts from start to finish, and a majority reported that they had listened to two of the episodes multiple times. 
Table 4. Podcast questionnaire results: motivation $(\mathrm{N}=25)$

\begin{tabular}{llll}
\hline Motivation & Mean & Std Dev. \\
\hline & A. Educational value of the podcasts & 3.68 & 1.345 \\
\hline 1 & I find listening to podcasts educational. & 3.44 & 1.261 \\
2 & I find listening to podcasts helps clarify and/or enhance my & & \\
3 & Listening to the podcasts helps alleviate my concerns about & 2.84 & 1.313 \\
4 & I would recommend that other students undertaking this subject & 3.48 & 1.085 \\
5 & Podcasting is not appropriate for teaching this subject. & 2.00 & 1.118 \\
6 & I find the topics presented are not appropriate to my needs. & 2.00 & 1.000 \\
\hline & B. Expectancy & & \\
\hline 7 & The topics selected are appropriate and useful. & 3.76 & 1.332 \\
8 & I find it easy to access the podcasted audio files. & 3.96 & 1.060 \\
9 & I find it easy to play the podcasted audio files. & 4.04 & .935 \\
10 & I find that listening to the podcasts is not a productive use of my & 2.32 & 1.069 \\
\hline & C. Affect & & \\
\hline 11 & I find podcasts to be entertaining. & 3.64 & 1.186 \\
12 & Listening to podcasts is trendy and socially acceptable. & 3.96 & 1.172 \\
13 & I enjoy the style and format of podcasts. & 3.88 & 1.301 \\
14 & Listening to podcasts makes me feel less anxious about the subject. & 3.36 & 1.186 \\
15 & I like podcasts that have been produced by my classmates best. & 3.56 & 1.158 \\
\hline & Total & 3.77 & 1.196 \\
\hline & & & \\
\hline
\end{tabular}

From a motivational perspective, as is shown in table 4 , the participants were generally positive $(M=3.77)$. In terms of educational value, the participants generally concurred that the podcasts were of educational value to them $(M=3.57)$ and that they were beneficial to their understanding of the subject content $(M=3.44)$. The participants stated that they would recommend using podcasts to other students studying the subject $(\mathrm{M}=3.48)$. They disagreed over whether the podcasts were appropriate to their needs or to the subject $(\mathrm{M}=2.00)$. Typically, the participants expressed feelings that suggested the podcasts did not wholly alleviate their concerns about subject-related matters, such as textbook criteria and assessment $(\mathrm{M}=2.84)$.

In terms of the expectancy component, the participants agreed that the topics in the podcasts were appropriate and useful $(M=3.76)$; they also found episodes easy to access and $(M=3.96)$ easy to play on their devices (4.04). The participants contradicted the statement that podcasts were a waste of their time $(M=2.32)$.

The participants' responses spoke highly of the podcasts' social and trendy style; identifying this amongst their other affective qualities (3.96) and (3.88) respectively. They found the podcasts entertaining $(\mathrm{M}=3.64)$ and observed that their classmates' podcasts were better than the audio files that they listened to in the traditional classroom setting $(\mathrm{M}=3.56)$. In addition, the participants agreed that podcasts made them feel less anxious about engaging with the subject $(\mathrm{M}=3.36)$.

\subsection{Testing Question Three}

In order to answer the third question posed in this study: What are EFL students' attitudes towards using podcasts in EFL classrooms, regarding listening comprehension? A questionnaire was used. As is shown in table 5; from the analysis the participants seem to have had a significantly positive attitude towards podcast-based learning following their exposure to their in course podcasts $(\mathrm{M}=3.77)$. 
Table 5. Podcast questionnaire results: attitude towards using podcast $(\mathrm{N}=25)$

\begin{tabular}{llll}
\hline Attitudes & Mean & Std Dev \\
\hline 16 & I find the number of podcast episodes to be appropriate. & 4.00 & 1.118 \\
17 & I find the length of the podcast episodes to be appropriate. & 4.40 & .816 \\
18 & 3.88 & 1.013 \\
19 & I find the listening exercises to be useful. & 4.00 & 1.000 \\
20 & I find the topics on the whole to be relevant to my learning. & 3.76 & 1.052 \\
21 & The topics covered by the podcasts appeal to my interest. & 3.20 & 1.225 \\
22 & I find the overall technical quality to be good. & 3.60 & 1.414 \\
23 & Working with classmates to create podcasts enhanced my collaborative work. & 4.04 & .935 \\
24 & Face-to-face lectures are sufficient for my learning & 2.40 & 1.291 \\
25 & I would like to use podcast in other EFL classes. & 2.84 & 1.434 \\
26 & It would be better to have access to transcripts for the podcasts. & 3.88 & 1.236 \\
27 & Podcasts are easy to create. & 3.76 & 1.012 \\
28 & Podcasts are easy to download. & 3.96 & 1.098 \\
29 & I would like to listen to one speaker on the podcast. & 2.68 & 1.345 \\
30 & I listen to podcast immediately after I have downloaded it. & 4.24 & 1.128 \\
\hline Total & 3.77 & 1.20 \\
\hline
\end{tabular}

In general, there was moderate to strong agreement among the participants in regards to most of the statements describing attitudes towards using podcasts (statements 16-20, 22-23, 26-28 and 30), with moderate agreement assumed at a mean score of 3.40-4.20 and strong agreement at 4.20 and above. The highest mean (4.40) was for participant's agreement over the ideal length of podcast episodes, which was between 2-5 minutes. They remained neutral (i.e., they neither agreed nor disagreed) with statements 21 and 25 about the appeal of the topics included in the podcast and about using podcasts in other EFL classes. However, the participants disagreed with statements 24 and 29 with means $(\mathrm{M}=2.40$ and 2.68) respectively, which suggested face-to-face classes are sufficient for their learning, and the usefulness of listening to only one speaker in the podcast episodes.

\section{Discussion}

With regards to the first question, whether podcasts enhance comprehension; the findings suggest that podcasts can enhance students' listening comprehension better than traditional classroom instruction. These results are in agreement with other studies, which found significant differences in student performance when students were exposed to podcasts (Lu, 2007; Anusiene \& Kavaliauskiene , 2009) for listening comprehension. Reasons for this positive finding includes the fact that podcasts provide an attractive opportunity to expose students, especially advanced language learners, to authentic conversations that can help to increase their listening comprehension and vocabulary acquisition. Moreover, participants gained confidence in their abilities to comprehend English overall, as Lu (2007) also mentioned.

The second question in the study explored whether podcasts enhance motivation among students in EFL classrooms in the case of listening comprehension. Analysis shows that participants in the experimental group achieved positive agreement, demonstrating that they were motivated by podcast in their learning $(M=3.77)$. In brief, participants believed that they were able to use podcasts in their learning successfully because they were easy to download and play on their mobiles. Also, podcasts had value to them, as the content was educational and related to their learning. In addition, they expressed the fact that they were emotionally responsive to podcasts because of their social caché. These results are in agreement with other studies that found podcasts can enhance language learners' motivation (McLoughlin, Leen \& Chan, 2007; Chan, Chi, Chin \& Lin, 2011).

Reasons for these positive findings are that, as Sze (2006) indicated; once students have produced podcasts and uploaded them online, they can then be downloaded by anyone from around the world, suggesting the existence of a huge authentic audience beyond the classroom. In this study, the participants, during the time spent rehearsing and recording their episodes, were took great care over their pronunciation and intonation; thus, they often recorded and re-recorded to ensure that they did not make mistakes because they were aware that their podcast channel was already online on the iTunes store. Moreover, during the duration of the study additional 
students volunteered to produce podcasts after listening to their peers' 'recordings', supporting the assertion that podcasting increased their intrinsic motivation as Hegelheimer and O-Bryan (2007) suggested.

The third question explored in the study concentrated on EFL students' attitudes towards using podcasts in the EFL classroom, especially when evaluating listening comprehension. These results support those of other studies, which found that EFL students have a positive attitude towards using podcasts in EFL classrooms in regards to listening comprehension ( $\mathrm{Li}, 2010$; Menezes \& Morera, 2009). In terms of attitude, the highest agreement related to participants is the length of the podcast, which was appropriate to them (from 2 to 3 minutes). According to Li (2010), one of the obstacles that learners encountered when listening to podcasts was disinterest, if they were overly long. In this study, the participants wrote and produced podcasts short podcasts that contrasted with the audio tapes that are played in the class by the teacher for this reason. One advantage to students when writing their own podcast episodes was the sense of collaboration and teamwork engendered. During the writing of their episode scripts the students negotiated what to topic and format to select and explain and how to present a radio format. This involved the process of writing and rewriting cooperatively and making decisions, sharing ideas and learning from one another. Thus, it was not surprising that the participants' attitude towards the collaborative work element showed positive agreement. In addition, their disagreement over listening to one speaker on the podcast was another indication that they had a positive attitude towards collaborative work in podcasts. Another point that they disagreed with was that face to face instruction was sufficient for their learning, indicating that they need an outside classroom tool to enhance their learning as podcasts might bridge this gap.

The participants were neutral over the selection of the podcast topics as they appealed to their interests. As an explanation, the topics selected were based on their syllabus, so they would be relevant to their learning. The syllabus in general did not appeal to their interest; thus, some of the podcast material appealed to the students interests, whereas other topics did not. The other neutral statement suggested that the participants were not sure if the audio podcasts were effective for teaching other English skills such as grammar, writing, reading, speaking, and vocabulary acquisition. Some of these were supposed to require visual aids and explanation by the teacher. Thus, as the students were using only audio podcasts in this study, this limited the podcasts maximum potential. Different results might have been obtained had they used formats such as video or picture supported podcasts.

This study contradicts that conducted by Clark et al. (2009) which revealed opposite findings. In that study, the participants rejected the mobile potential of podcasting in favor of traditional study habits. As the author suggested, reasons for this may include time pressure, the students' English language skills and their knowledge of the medium. In this study, none of these issues proved to be obstacles, which explains why the findings would more logically be positive.

\section{Conclusion and Recommendations}

\subsection{Summary of Findings}

The primary aim of this study has been to determine whether podcasts affect Saudi participants' listening comprehension. The findings revealed positive results. Thus, this study supports the notion that the use of podcasts can make a positive and significant difference to the listening comprehension for EFL higher education students.

If research is to reveal to practitioners the best way to use podcasts in higher education it will be important to focus on podcasts' pedagogical design. There is no question that podcasting is a valuable tool for teachers and students, as, in the contemporary environment a mobile education tool increases the probability that students will feel engaged and motivated when they appreciate the authenticity of their work, and their autonomy. It was observed during the study that the collaborative environment enforced team building skills and the students' sense of community and thereby their enjoyment in the task. Finally, podcasting was found to connect positively with larger numbers of learners than traditional media.

\subsection{Recommendations}

Although the results of this study are broadly positive, there are several areas worth investigating further. Initially, the current study applied to Saudi female higher education students; however, it is reasonable to suggest a potential value when using podcasts with younger learners of both genders. Secondly, this study was conducted to improve listening skills only, but could be extended to support other language skills. The podcast episodes used in this study were produced by the same participant groups as the students using the podcasts; other types of podcasts studies could utilize authentic podcasts with advanced learners in the higher education setting. This study is quantitative, and qualitative studies could contribute an added dimension.

\section{References}

Al-Fahad, F. N. (2009). Students' Attitudes and Perceptions towards the Effectiveness of Mobile Learning in 
King Saud University, Saudi Arabia. The Turkish Online Journal of Educational Technology, 8(2), Article 10 .

Al-Omar, B. A. (2004). Data Statistical Analysis in Scientific Research: Using SPSS. Riyadh: Institute of Health studies.

Al-Shehri, S. (2011). Context in Our Pockets: Mobile Phones and Social Networking as Tools of Contextualizing Language Learning. 10th world conference on mobile and contextual learning, Beijing, China, 18(2), October.

Anusienè, L., \& Kavaliauskienė, G. (2009). English for Specific Purposes: Podcasts for Listening Skills. Edukologija, 17(2), 2009. Retrieved from http://dx.doi.org/ 10.3846/1822-430X.2009.17.2.28-37

BBC News. (2005). Wordsmiths hail podcast success. Retrieved December 7, 2005, from http://news.bbc.co.uk/go/pr/fr/-/2/hi/technology/4504256.stm

Burston, J., Song. W., \& Zhang, H. (2011). Reexamining the Effectiveness of Vocabulary Learning Via Mobile Phones. Turkish Online Journal of Educational Technology, 10(3), 203-214.

Chan, A., Lee, M., \& McLoughlin, C. (2007). Promoting Engagement and Motivation for Distance Learners through Podcasting. Budapest, Hungary: European Distance and E-Learning Network.

Chan, M., Chi, W., Chin, N., \& Lin, Y. (2011). Students' perceptions of and attitudes towards podcast-based learning - A comparison of two language podcast projects. Electronic Journal of Foreign Language Teaching, 8(1), 312-335.

Chang, C., Chen, I., \& Yen, J. (2012). Effects of presentation mode on mobile language learning: A performance efficiency perspective. Australasian Journal of Educational Technology, 28(1), 122-137.

Clark, S., Giuseppe, C., Scott, K., Sutton-Brady, C., \& Taylor, L. (2009). The Value of Using Short-Format Podcasts to Enhance Learning and Teaching. ALT-J Research in Learning Technology, 17(3), 219-322. Retrieved from http://dx.doi.org/ 10.1080/09687760903247609

Dennett, C., Edirisingha, P., Mobbs, M., Mobbs, R., \& Salmon, G. (2008). How to Create Podcasts for Education. United Kingdom: Open University Press.

Edirisingha, P., Fothergill, J., \& Salmon, G. (2007). Profcasting - A Pilot Study and Guidelines for Integrating Podcasts in a Blended Learning Environment. Beyond Distance Research Alliance University of Leicester Pre-publication version. January.

Hegelheimer, V., \& O-Bryan, A. (2007). Integrating CALL into the Classroom: the Role of Podcasting in an ESL Listening Strategies Course. ReCALL, 19(2), 162-180. http://dx.doi.org/10.1017/S0958344007000523

Howell, J., \& Lee, K. (2007). M-Learning: Finding A Place For Mobile Technologies Within Tertiary Educational Settings. Singapore: Ascilite.

Kies, C., Khumalo, Y., Mapuva, J., \& Stoltenkamp, J. (2011). Rolling out Podcasting to Enhance Teaching and Learning: A Case of the University of the Western Cape. International journal of instructional technology and distance learning, $8(1)$.

Kukulska-Hulme, A., \& Lesley S. (2007). An Overview of Mobile Assisted Language Learning: Can mobile devices support collaborative practice in speaking and listening? Euro CALL 2007. http://dx.doi.org/10.1017/S0958344008000335

Li, H. (2010). Using podcasts for learning English: perceptions of Hong Kong Secondary 6 ESL students. Journal - Début: The undergraduate journal of languages, linguistics and area studies, 1(2), 2010.

Lu, J. (2007). 'Podcasting: A fresh solution for old problems'. In M. Thomas (Ed.), Wireless Ready e-Proceedings: Podcasting Education and Mobile Assisted Language Learning, 83-95.

Mahjouri, J., \& Purnell, M. (2007). 'Broadcasting Library Information'. A Podcast Project at Charles Darwin University Library, Conference Australian Library and Information Association, October, 6, 2007.

Oxford University Press. (2005). The New Oxford American Dictionary (2nd Ed.). New York. Oxford University Press.

McMinn, S. (2008). Podcasting Possibilities: Increasing Time and Motivation in The Language Learning Classroom. European Institute for E-Learning. Learning Forum 2008, 212-215.

Menezes, C. Q., \& Moreira, F. L. (2009). 'In the Pursuit of M-Learning - First Steps in Implementing Podcast 
among K12 Students in ESL'. Challenges 2009 - Actas da VI Conferência Internacional de TIC Na Educação (pp. 91-107). Braga: CCUM.

Pals, T., Randell, T., \& Shawback, M. (2005). Podcasts: A Language Lab in Your Pocket. KOTESOL Proceeding 2005. From Concept to Context: Trends and Challenges.

Panday, P. (2009). Simplifying Podcasting, International Journal of Teaching and Learning in Higher Education, 20(2), 251-261.

Rivera, J. (2010). Authentic Oral Interaction in the EFL Class: What It Means, What It Does not, Teachers Professional Development, 12(1), 47-61.

Rosell-Aguilar, F. (2007). Top of the Pods - In search of a podcasting "podagogy" for language learning. Computer Assisted Language Learning, 20(5), 471-492. http://dx.doi.org/10.1080/09588220701746047

Sze, P. (2006). Developing Students' Listening and Speaking Skills Through ELT Podcasts. Educational Journal, $34,115-134$.

Vandergrift, L. (1997). Facilitating second language listening comprehension: acquiring successful strategies, ELT Journal, 53(3), 168-176. http://dx.doi.org/10.1093/elt/53.3.168

Zarina, M. (2009). The Effects of Utilising ESL Podcast in Phonetics Instructions. Monograph. USM E-Prints. Universiti Sains Malaysia.

\section{Copyrights}

Copyright for this article is retained by the author(s), with first publication rights granted to the journal.

This is an open-access article distributed under the terms and conditions of the Creative Commons Attribution license (http://creativecommons.org/licenses/by/3.0/). 